\title{
A Case Study of Language Development of Preschool Age Child With Cochlear Implant in Sign/Bilingual Program*
}

\author{
Yu-Chih Huang \\ National Pingtung University, Pingtung, Taiwan
}

\begin{abstract}
Whether the preschool age child with cochlear implant should use sign has always been a controversial issue, especially for those hearing parents with deaf children. The purpose of this study was to explore the development of spoken and sign language in children with cochlear implants in sign/bilingual program, and to understand the effect of sign language in their spoken language development. A case study of a sign/bilingual child with a cochlear implant is presented. Data collection in the research included interviews with mother and teachers, class observations, and Joe's language performances in reading class. To realize Joe's whole skill, we collected more data from standardized tests, words expression, reading comprehension test, and retelling story. The research duration was eighteen months. Research findings also reveal that sign language promoted the Joe's spoken language development, but two language abilities did not occur in parallel. It is most important for them to learn a natural and complete language in sign/bilingual program during the early years of life.
\end{abstract}

Keywords: child with cochlear implant, language development, sign/bilingual program

\section{Introduction}

Most parents and teachers expect their children to develop spoken language abilities, not to use sign language, and attend school in regular classroom settings once their children have a cochlear implant (Geers, 2006; Hyde, Punch, \& Komesaroff, 2010). Within the last 20 years, researchers and educators have made considerable progress in understanding the development of spoken language and speech in children with cochlear implants (Archbold \& Mayer, 2012). The variability among children's outcomes with cochlear implants means that it is difficult to predict outcomes accurately for an individual child (Hyde \& Punch, 2011). A review of research related to sign use for children with cochlear implants and how spoken language can be actively developed, valued, and used in approaches that include sign will be more readily considered (Nussbaum \& Scott, 2011). The modes of communication used by children with cochlear implants and the role of sign language in the children's language development remain a challenge.

The theme of the conference held by the Laurent Clerc National Deaf Education Center at Gallaudet University in 2002 was "Cochlear Implants and Sign Language: Putting It All Together," and focusing on how sign language can fit together with the technology of cochlear implants (Nussbaum, LaPorta, \& Hinger, 2002). They provided special programming for children using cochlear implants and also learning American Sign Language (ASL) in a school with sign/bilingual approach (Seal et al., 2005). Sign/bilingual approach, which

\footnotetext{
*Acknowledgements: This research is part of the Ministry of Science and Technolog (MOST) Project, and is supported by the MOST grant. We would like to acknowledge for the supporting.

Yu-Chih Huang, Ph.D., associate professor, Department of Special Education, National Pingtung University.
} 
posits that all language share core proficiencies and that skills developed in a first language will transfer to skills in second language, is predicated, at least, in part on Cummins's (1989) linguistic interdependence theory. Sign/bilingual program provides rich language environments, in the expectation that the children's language skills will develop through natural interactions with fluent signers, and spoken language will become their second language (Simonsen, Kristoffersen, Hyde, \& Hjulstadt, 2009; Preisler, 2007; Spencer \& Marschark; 2010).

Many people believe that learning sign language will hinder the development of spoken language after receiving cochlear implants, and so far, there is not enough evidence to explain why children getting cochlear implants need to learn sign language (Lyness, Woll, Campbell, \& Cardin, 2013; Nussbaum \& Scott, 2011). Rowe and Goldin-Meadow (2009) evidenced that early gestural communication was an important link to spoken language acquisition in typically developing infants. There was no evidence that natural sign language could decrease spoken language acquisition for Children who used ASL before getting a cochlear implants (Yoshinaga-Itano, 2006).

The purpose of this study was to explore the development of spoken and sign language in children with cochlear implants in sign/bilingual program, and to understand the effect of sign language in their spoken language development.

\section{Methods, Participant, and Background}

Joe was identified as having a bilateral, severe-to-profound hearing loss at the age of 12 months because of large vestibular aqueduct syndrome (LVAS). He used hearing-aids from the age of 12 months and got a cochlear implant at the age of 23 months. Professionals at the hospital strongly encouraged Joe's parents to speech with him. He was received auditory-verbal method training in lasting three years after implantation. He had no obvious progress in spoken language, and always used body language to communicate. His mother doubted the effectiveness of the cochlear implant. Even the doctor indicated the implantation was successful.

Joe's mother got the information about the sign/bilingual training program in Kaohsiung city from the auditory-verbal therapist. His mother and grandma began to learn sign language in a parents program with a teacher of the deaf. Both parents wished to continue to sign with Joe, because they felt their interaction had improved since they began to use sign language at home. That professionals at the auditory-verbal center supported Joe's oral language development once a week.

Joe's task scale of Wechsler Preschool and Primary Scale of Intelligence-Revised (WPPSI-R) performance on intelligence quotient (IQ) was 113 , and the percentile was 81 . Joe's personality was lively and smart and he could draw inferences about other cases from one instance. His brother uses a hearing aid and communicates in spoken language.

\section{Intervention Program and the Context}

The early intervention for Joe was a day care center of sign/bilingual program. There were six deaf or hard-of-hearing peers between the age of three and six, and who continued to be exposed to sign language at school and home. Joe was the only one child with cochlear implant. Three students had not any hearing aids because of ineffectiveness, and another two students with hearing aids. Joe's center-based services included sign language support, and resource support from the staffs and sign language interpreter. Three hearing teachers in the sign/bilingual day care center were fluent in the native sign language. The center's main objects were being responsible for sign language interpreter training program in Kaohsiung City and offering sign 
language interpreter service for the deaf community. The staffs were hearing people and deaf people working together. They all used sign language and learned how to communicate with the six children in spoken and sign language. In addition, a deaf teacher from Taipei attended reading class once a week lasting eighteen months.

The curriculum followed the preschool special education curriculum for all special needs students, with an additional supplement designed specifically for deaf and hard-of-hearing children. The teachers focused on children's acquiring basic concepts and language through playing activities, group discussions, and picture book reading using sign language and spoken language - assuring that the children saw Chinese print in meaningful situations. Activities included keeping a daily journal, and mathematics, science, and social studies. Joe's sign/bilingual context as shown in Figure 1:

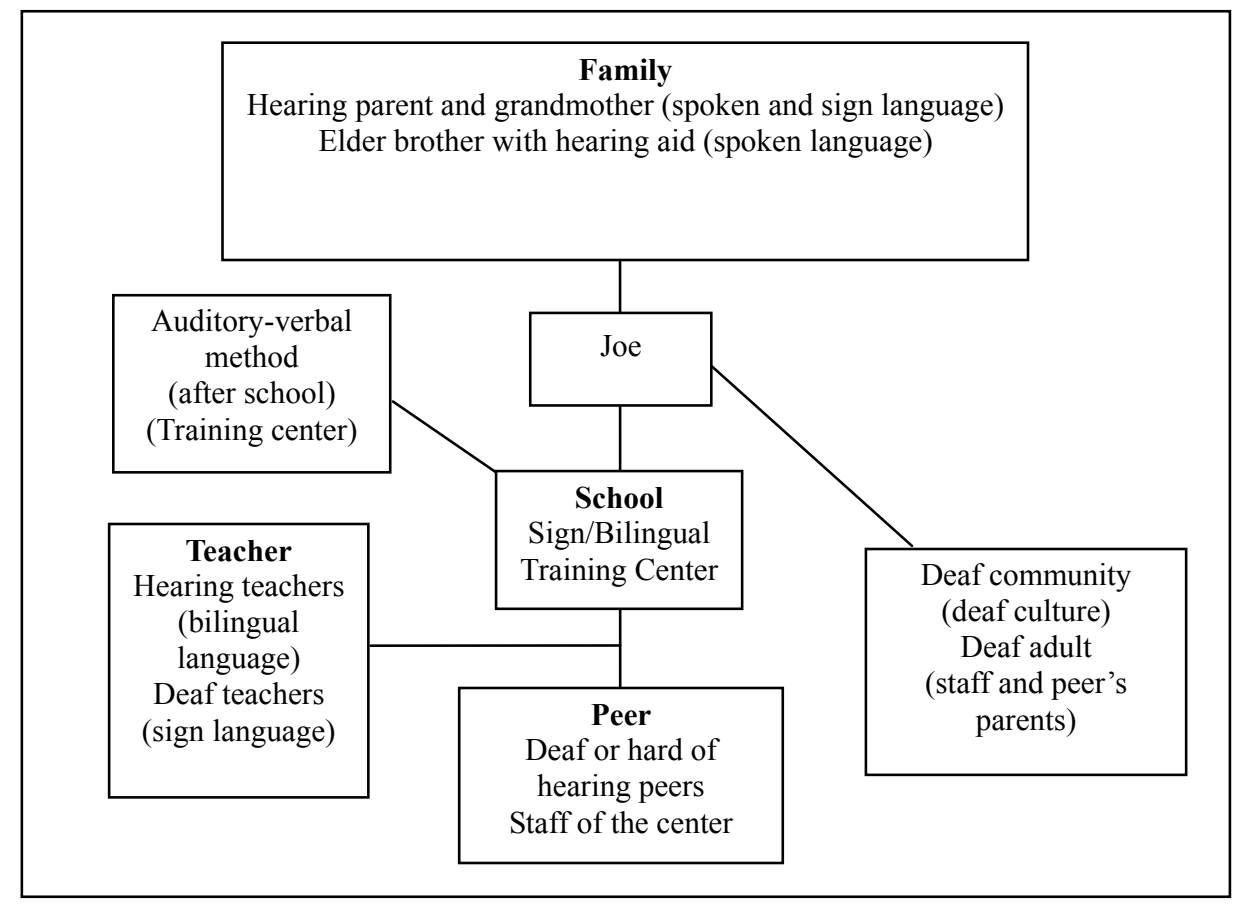

Figure 1. Joe's sign/bilingual context.

\section{Data Collection and Analysis}

To realize Joe's language development in bilingual context, data collection in the research included interviews with mother and teachers, each time an hour of classroom observation twice a week, and Joe's language performances in reading class. To realize Joe's whole skill, we collected more data from standardized tests, words expression, reading comprehension test, and retelling story. The research duration was eighteen months.

The instrumentals of the research were as follows: task scale of WPPSI-R (Chen \& Chen, 2000), the Peabody Picture Vocabulary Test-Revised (PPVT-R) (Lu \& Liu, 1994), and Mandarin Auditory Speech Perception Capability Task (Chen, 1999). Furthermore, the non-standardized evaluation for reading picture books included words expression tests, the multiple-choice reading comprehension test, and assessment of retelling story. The tests were used in both spoken and sign language.

The accuracies of words expression tests and multiple-choice reading comprehension test were calculated as follows: the numbers of correct items divided by the numbers of sub-items. For evaluating retelling story 
ability, we adopted the phrases extent, the sentence complexity, semantic depth, and grammar correction to be the analyze indexes. For evaluating the story structure, we adopted Wang's (2005) "the criteria for scoring of story structures" (see Table 1). To evaluate the development stage of retelling story and realize Joe's language expression and receptive ability, we adopted Chi's (2009) "children narrative skill development summary" [according to Westby's (1989) and Applebee's (1978) theories] to be the framework for analyzing.

Table 1

The Criteria for Scoring of Story Structures

\begin{tabular}{|l|l|l|}
\hline Elements of the story structure & Descriptions & Scoring range \\
\hline Characters & $\begin{array}{l}\text { Recognizing the character (1 point); and describing the features of the } \\
\text { character (1 point). }\end{array}$ & $(0$ to 2$)$ \\
\hline Setting & $\begin{array}{l}\text { Recognizing one primary or two secondary locations (1 point); and } \\
\text { recognizing the time (1 point). }\end{array}$ & $(0$ to 2$)$ \\
\hline Problem & $\begin{array}{l}\text { Recognizing a concept of the event (1 point); and describing two-thirds } \\
\text { concepts of the events completely (2 points). }\end{array}$ & $(0$ to 2) \\
\hline Process & $\begin{array}{l}\text { Recognizing the event (1 point); describing two-thirds of the events } \\
\text { completely (2 points); and describing three events (6 points). }\end{array}$ & $(0$ to 6$)$ \\
\hline Outcome & $\begin{array}{l}\text { Recognizing a concept of the event (1 point); and describing two-thirds } \\
\text { concepts of the events completely (2 points). }\end{array}$ & $(0$ to 2) \\
\hline Reaction & $\begin{array}{l}\text { Recognizing the action of the character (1 point); describing the feelings (2 } \\
\text { points); and describing three events (6 points). }\end{array}$ & $(0$ to 6$)$ \\
\hline
\end{tabular}

\section{Results}

\section{The Decision-Making Process of Sign/Bilingual Program}

Cochlear implant has provided profoundly deaf children with new opportunities to develop intelligible speech effectively. Much attention has focused on which communication mode of this group of children with cochlear implants adopted (Geers, 2006). We interviewed Joe's mother to understand her perspectives on communication and why choosing the sign/bilingual program at three years post implantation. Joe's mother said that Joe had still not much progress in oral language after three years of implantation. She was worried about it. The auditory-verbal therapist recommended her to use visual strategies, targeting new words in sign language and checking for understanding to help his comprehension of the language. Then, she visited sign/bilingual program and held positive impressions for sign language. Parents agreed that overt code switching with Joe was needed in order to develop bilingual skills successfully for him. Joe was enrolled in a sign/bilingual preschool program when he was almost five years old.

Joe's mother wants him to participate in the sign/bilingual program. She thought learning sign language made Joe's oral language better. However, his three classmates rely on sign language to communicate and teachers communicated to students more often using sign language, his mother worried that the school did not provide adequate oral environment and affect the development of Joe's spoken language. She reminded the teacher to use sign language and spoken language at the same time. The research found that, although Joe's mother chose the sign/bilingual program, she wanted to develop Joe's oral skills with a sign/bilingual program.

\section{Speech Production and Speech Intelligibility}

When Joe entered the sign/bilingual class initially, he would like to imitate other students' behaviors in speech. For example, he would like to use "Ah...Ah...Ah." The research found that the interaction between Joe and his mother is isolated. Sometimes, Joe played by himself and ignored the discourse from his mother. Joe's expression of the sentence was brief. He spoke rarely at half-hour observation. His mother used spoken 
language to him. Joe's answer was brief only one to four words and he rarely used spoken language. For the interactive model between Joe and his mother, it was less sign language. Joe's oral language was unintelligibility for strangers.

When Joe received bilingual education six months later, the researcher began to observe his language learning performance. In the reading class, Joe could use more sign language, but less spoken language in the class. Joe interacted with the deaf teacher frequently. After nine months later, Joe could express the complete sentences and describe life events in sign language. In the hearing teacher's class, they use bilingual interaction. Joe usually answered in sign language or spoken language alternatively. Joe usually interacted with other students in sign language. Joe's spoken language expression was less than four words. His sign language was better than spoken. Preisler, Tvigstedt, and Alstrom (2002) concluded that the children who developed the best sign language skills also had the highest-level skills in spoken language. Increases in the two abilities tended to occur in parallel. However, in this research, the child with cochlear implant achieving higher levels of sign language skill did not assure a parallel advance in spoken language skills. This might be because of the use of cochlear implant, so that he performed in the auditory skills better than the same age hearing impairment students. However, his discrimination in the vowel and tone was poor performance. Compared with the hearing students of the same age, his discrimination of tone, vowel and consonant, phrase, sentence comprehension, and orders were lower than the norm.

\section{Words Expression and Reading Comprehension}

In 18 months observation duration, we get Joe's formative assessment data in 16 picture books. The evaluation task is a words expression test. He scored $54.55 \%-100 \%$ accuracy in spoken words expression, and the average was $81.22 \%$ accuracy. He scored $87.5 \%-100 \%$ accuracy in sign words expression, and the average was $97.39 \%$ accuracy.

Joe's performance in PPVT-R (Lu \& Liu, 1994) was different in sign languages and spoken language. The PPVT-R includes 125 items. He made 11 correct words when teacher used in spoken language testing, but 98 correct words in sign language testing. We consider that sign language is a visual language. It is easy for Joe to understand because of concrete. The percentile for Joe's oral language words comprehension was six. Joe performs better in sign words expression.

Furthermore, according to the multiple-choice reading comprehension test analyzing in 16 picture books, Joe scored $0 \%-100 \%$ accuracy in oral language, and the average was $27.76 \%$ accuracy. He scored $25 \%-100 \%$ accuracy in sign language, and the average was $67.11 \%$ accuracy. In reading comprehension, the sign language performance was also better than oral language performance. Thus, the research suggested Joe's reading comprehension test performances were affected by hearing comprehension ability, and not affected by cognition ability.

\section{Retelling Story}

Joe's language expression ability in this research was depending on his retelling story contents in five picture books (Crocodile and the Dentist; The Very Hungary Caterpillar; One Rainy Day; Guess How Much I Love You; and Hayaku Aitaina). In the assessment task, Joe used both sign language and spoken language to retell each story. Joe's phrases were abundant in both sign and spoken language. His oral expression would be influenced by the grammar of the sign language. He tended to use sign language. Compared with the spoken language, he was more able to use sign language to express. In the complexity of sentence structure, he used 
only simple sentences in spoken language and sign language. In the meaning depth of semantics, he used more superficial meaning than deeper ones. In the correction of grammar in speech language, he always used two to four words-combinations and less completely sentence. It was not natural Taiwan sign language grammar in sign language expression. It related to the grammar of manual code language. Furthermore, according to the criteria for scoring of story structures as shown in Table 1, Joe scored $60 \%$ in retelling story structure with sign language and $58 \%$ with oral language.

Joe's retelling story development stages was analyzed. The research found Joe's sign language development stage near five years old of hearing children was better than his spoken language development stage near four to four and half years old of hearing children. Furthermore, his language development was making progress continuously. It is quite evident that Joe was continuing to develop more sophisticated auditory comprehension skills and speech skills. He could participate in a variety of sounds in the environment, hear the whisper, and identify the noise in the environment. Joe was also developing oral and auditory language skills related to academic activities and was able to answer questions related to stories, activities, and other academic subject.

\section{Discussion and Conclusion}

The factors that predict the best outcomes for bilingual language development for a child with a cochlear implant are early age of implantation (before age two), two languages used in the home, parent involvement, motivation for bilingual learning, and opportunities to use both languages in meaningful contexts with native users (McConkey, 2007). For Joe who came from hearing family, spoken language was the language used at home. Although his implantation was before age two, weak speech perception skills caused by LVAS and the lack of natural sign language used at home had an impact on the language development outcomes of him. There might be debates on the use of sign for children following implantation, but Joe's case demonstrates the potential for children with cochlear implants to develop oral language skills by sign language. While more research is needed. It should consider supporting bilingual families to use sign language with their children.

In addition, because of the difference between sign language and spoken language, oral language expression was limited by the influence of sign language, resulting in its semantics unclear and difficult to understand. His speech expression was affected by sign language grammar. Joe's auditory perception capability, speech perception, and auditory comprehension were less than the hearing norm. For teachers, it is a key suggestion to develop bilingual in parallel during the teaching processes.

The influence of sign language towards spoken language can be positive or negative. The research noted that achieving higher levels of sign language skills did not assure a parallel advance in spoken language skills. Yoshinaga-Itano and Sedey (2000) reported that children in the United States with higher levels of languages skills at early ages, regardless of mode, had the best speech skills at later ages. However, the findings of researches suggest that sign language is an appropriate early intervention language for the young children with cochlear implants caused by LVAS.

According to the data analyzing, our conclusions are as follows:

1. A young children with cochlear implants, his parents should make decision on choosing the sign/bilingual program when their child in spoken language learning is less progress. The hearing parents should support sign language learning and offer the rich language context; 
2. Research findings also reveal that sign language promoted Joe's spoken language development, but they did not occur in parallel;

3. The performances of words expression and reading comprehension of preschool child with cochlear implant in sign language were better than spoken language. However, Joe's expression was not natural sign language in retelling story. It is most important for children to learn a natural and complete language in sign/bilingual program during the early years of life.

\section{References}

Applebee, A. (1978). The child's concept of story: Ages two to seventeen. Chicago, USA: University of Chicago Press.

Archbold, S., \& Mayer, C. (2012). Deaf education: The impact of cochlear implantation? Deafness and Education International, 14(1), 2-15.

Chen, H. C. (1999). Mandarin auditory speech perception capability of hearing impaired children at age three to eight. Bulletin of Special Education and Rehabilitation, 7, 51-78.

Chen, J. H., \& Chen, H. Y. (2000). Manual for the Wechsler Preschool and Primary Scale of Intelligence-Revised. Taipei, Taiwan: Chinese Behavioral Science Corporation.

Chi, B. S. (2009). Language development of the children. Taipei, Taiwan: Psychological Press.

Cummins, J. (1989). A theoretical framework of bilingual special education. Exceptional Children, 56(2), 111-119.

Cummins, J., \& Swain, M. (1986). Bilingualism in education: Aspects of theory, research, and practice. London, U.K.: Longman.

Geers, A. M. (2006). Factors influencing spoke language outcomes in children following early cochlear implantation. Advances in Otorhinolaryngology, 64, 50-65.

Graney, S. (1997). Where does speech fit in? Spoken English in a bilingual context. Washington, D.C., USA: Laurent Clerc National Deaf Education Center, Gallaudet University.

Guiberson, M. M. (2005). Children with cochlear implants from bilingual families: Considerations for intervention and a case study. The Volta Review, 105(1), 29-40.

Hyde, M., \& Punch, R. (2011). The modes of communication used by children with cochlear implants and the role of sign in their lives. American Annals of the Deaf, 155(5), 535-549.

Hyde, M., Punch, R., \& Komesaroff, L. (2010). Coming to a decision about cochlear implantation: Parents making choices for their deaf children. Journal of Deaf Studies and Deaf Education, 15(2), 162-178. doi: 10.1093/deafed/enq004

Lu, L. \& Liu, H. S. (1994). The Peabody picture vocabulary test-revised. Taipei, Taiwan: Psychological Publishing.

Lyness, C., Woll, B., Campbell, R., \& Cardin, V. (2013). How does visual language affect crossmodal plasticity and cochlear implant success? Neuroscience \& Biobehavioral Reviews, 37(10), 2621-2630. doi: 10.1016/j.neubiorev.2013.08.011

Marschark, M., Lang, H. G., \& Albertini, J. A. (2002). Educating deaf students: From research to practice. Washington, D.C., USA: Gallaudet University Press.

McConkey, R., A. (2007). Clinical management of bilingual families of children with cochlear implants. Loud \& Clear, 1, 1-12.

Nussbaum, D., LaPorta, R., \& Hinger, J. (2002). Cochlear implants and sign language: Putting it all together, identifying effective practices for educational settings. Conference Proceedings of Laurent Clerc National Deaf Education Center, Gallaudet University, Washington, D.C., USA.

Nussbaum, D., \& Scott, S. (2011). The Cochlear Implant Education Center: Perspectives on effective educational practices. In R. Paludneviciene \& I. Leigh (Eds.), Cochlear implants: Evolving perspectives (pp. 175-205). Washington, D.C., USA: Gallaudet University Press.

Preisler, G. (2007). The psychosocial development of deaf children with cochlear implants. In L. Komesaroff (Ed.), Surgical consent: Bioethics and cochlear implantation (pp. 120-136). Washington, D.C., USA: Gallaudet University Press.

Preisler, G., Tvingstedt, A., \& Ahlstrom, M. (2002). A psychosocial follow-up study of deaf preschool children using cochlear implants. Child: Care, Health, and Development, 28(5), 403-418.

Rowe, M., \& Goldin-Meadow, S. (2009). Differences in early gesture explain SES disparities in child vocabulary size at school entry. Science, 323(5916), 951-953. doi: 10.1126/science.1167025

Seal, B., Nussbaum, D., Scott, S., Waddy-Smith, B., Clingempeel, K., \& Belzner, K. (2005, November). Evidence for sign-spoken language relationships in children with cochlear implants. Paper presented at the American Speech, Language, and Hearing Society Annual Conference, San Diego, C.A., USA. 
Simonsen, E., Kristoffersen, A., Hyde, M. B., \& Hjulstadt, O. (2009). Great expectations: Perspectives on cochlear implantation of deaf children in Norway. American Annals of the Deaf, 154(3), 263-273.

Spencer, P. E., \& Marschark, M. (2010). Evidence-based practice in educating deaf and hard of-hearing students. New York, USA: Oxford University Press.

Wang, C. C. (2005). Teaching for story structure and sharing story of reading. Taipei, Taiwan: Psychological Press.

Westby, C. (1989). Assessing and remediating text comprehension problems. In A. G. Kahmi, \& H. W. Catts (Eds.), Reading disabilities: A developmental language perspective (pp. 199-260). Boston, M.A.: Little Brown.

Yoshinaga-Itano, C. (2006). Early identification, communication modality, and the development of speech and spoken language skills; Patterns and considerations. In P. Spencer \& M. Marschark (Eds.), Advances in the spoken language development of deaf and hard-of-hearing children (pp. 298-327). New York, USA: Oxford University Press.

Yoshinaga-Itano, C., \& Sedey, A. (2000). Speech development of deaf and hard-of-hearing children in early childhood: Interrelationships with language and hearing. In C. Yoshinaga-Itano, \& A. Sedey (Eds.), Language, speech, and social emotional development of children who are deaf or hard of hearing: The early years. Volta Review, 100(5), 181-211. 